JSPS Grants-in-Aid for Creative Scientific Research

Understanding Inflation Dynamics of the Japanese Economy

Working Paper Series No.62

Housing Prices in Tokyo: A Comparison of Hedonic and Repeat Sales Measures

\author{
Chihiro Shimizu \\ Kiyohiko G. Nishimura \\ and \\ Tsutomu Watanabe
}

First Draft: May 21, 2009

This version: August 24, 2010

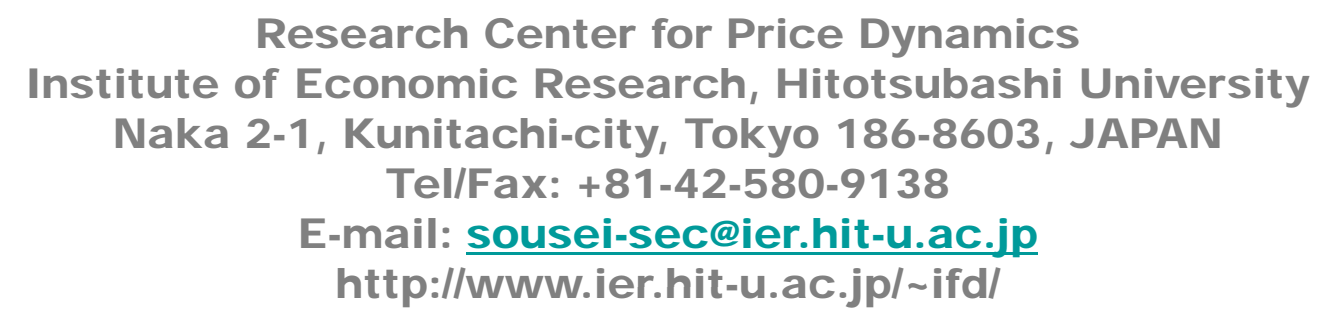




\title{
Housing Prices in Tokyo: A Comparison of Hedonic and Repeat Sales Measures
}

\author{
Chihiro Shimizu* Kiyohiko G. Nishimura ${ }^{\dagger} \quad$ Tsutomu Watanabe ${ }^{\ddagger}$ \\ First Draft: May 21, 2009 \\ This version: August 24, 2010
}

\begin{abstract}
Do indexes of house prices behave differently depending on the estimation method? If so, to what extent? To address these questions, we use a unique dataset that we compiled from individual listings in a widely circulated real estate advertisement magazine. The dataset contains more than 470,000 listings of housing prices between 1986 and 2008, including the period of the housing bubble and its burst. We find that there exists a substantial discrepancy in terms of turning points between hedonic and repeat sales indexes, even though the hedonic index is adjusted for structural changes and the repeat sales index is adjusted in the way Case and Shiller suggested. Specifically, the repeat sales measure signals turning points later than the hedonic measure: for example, the hedonic measure of condominium prices bottomed out at the beginning of 2002, while the corresponding repeat sales measure exhibits a reversal only in the spring of 2004. This discrepancy cannot be fully removed even if we adjust the repeat sales index for depreciation.
\end{abstract}

JEL Classification Number: C43; C81; R21; R31

Keywords: hedonic price index; repeat sales price index; aggregation bias; housing depreciation

\section{Introduction}

Fluctuations in real estate prices have a substantial impact on economic activity. In Japan, the sharp rise in real estate prices during the latter half of the 1980s and their

\footnotetext{
${ }^{*}$ Correspondence: Chihiro Shimizu, International School of Economics and Business Administration, Reitaku University, Kashiwa, Chiba 277-8686, Japan. E-mail: cshimizu@reitaku-u.ac.jp. We would like to thank Erwin Diewert, David Fenwick, Peter von der Lippe, and participants at the 11th Ottawa Group Meeting held in Neuchâtel, Switzerland for helpful comments on a preliminary draft. We also appreciate detailed comments from an anonymous referee and the editors of this journal. Nishimura's contribution was made mostly before he joined the Policy Board. This research is a part of the project entitled: Understanding Inflation Dynamics of the Japanese Economy, funded by JSPS Grant-in-Aid for Creative Scientific Research (18GS0101).

${ }^{\dagger}$ Deputy Governor, Bank of Japan.

${ }^{\ddagger}$ Research Center for Price Dynamics, Hitotsubashi University.
} 
decline in the early 1990s have led to a decade-long, or even longer, stagnation of the economy. More recently, the rapid rise in housing prices and their reversal in the United States have triggered a global financial crisis. Against this background, having a reliable index that correctly identifies trends in housing prices is of utmost importance.

A key starting point in estimating a housing price index is to recognize that the location, history, and facilities of each house differ to varying degrees. Even if the location and facilities are the same, the age of the buildings may differ, in which case the degree of deterioration varies accordingly. In other words, houses have "particularity with few equivalents." Given this special feature of houses and hence housing services, an important task for researchers is to make adjustments for differences in quality. There are two methods widely used by practitioners and researchers: the hedonic method and the repeat sales method. The purpose of this paper is to compare these two methods using a unique dataset that we have compiled from individual listings in a widely circulated real estate advertisement magazine.

Previous studies on house price indexes have identified several problems for each of the two methods. As for the repeat sales method, it has been pointed out that (i) repeat sales measures suffer from sample selection bias because houses that are traded multiple times have different characteristics than a typical house (Clapp and Giaccotto 1992); (ii) the assumption of no over time changes in property characteristics is too restrictive (Case and Shiller 1987, 1989; Clapp and Giaccotto 1992, 1998; Goodman and Thibodeau 1998; Case et al. 1991). On the other hand, the hedonic method is said to suffer from the following problems: (iii) the failure to include relevant variables in hedonic regression may result in estimation bias (Case and Quigley 1991; Ekeland et al. 2004); (iv) the assumption of no structural change (i.e., no over time changes in parameters) in the entire sample period is too restrictive (Case et al. 1991; Clapp and Giaccotto 1992, 1998; Shimizu and Nishimura 2006, 2007, Shimizu et al. 2010).

Given that true quality adjusted price changes are not observable, it is quite difficult to say which of the two measures performs better. However, at least from a practical perspective, it is often said that the repeat sales method represents a better choice because it is less costly to implement (e.g., Bourassa et al. 2006). However, as far as the Japanese housing market is concerned, there are some additional concerns about the repeat sales method. First, the Japanese housing market is less liquid than those in the United States and European countries, so that a house is less likely to be traded multiple times. ${ }^{1}$ Second, the quality of a house changes more rapidly over time in

\footnotetext{
${ }^{1}$ This may be partly due to the presence of legal restrictions on reselling a house within a short
} 
Japan because of the short lifespan of houses and the fact that - for various reasons renovation to restore the quality of a house plays a relatively unimportant role. This implies that depreciation plays a more important role in the determination of house prices, which is not fully taken into account in the repeat sales method. Given these features of the Japanese housing market, Shimizu et al. (2010) argue that, at least in Japan, the hedonic method is a better choice.

The rest of the paper is organized as follows. Section 2 presents an overview of the two methods and introduces five different indexes that we construct and then estimate in order to compare their performance. Section 3 provides a description of our dataset. The dataset we use in this paper is compiled from individual listings in a widely circulated real estate advertisement magazine. The dataset contains more than 470,000 listings of housing prices between 1986 and 2008, which includes the period of the housing bubble and its subsequent burst. Section 4 then presents the estimation results. We find that there exists a substantial discrepancy in terms of turning points between structural-change-adjusted hedonic and Case-Shiller-adjusted repeat sales price indexes. Specifically, the repeat sales measure signals turning points later than the hedonic measure: for example, the hedonic measure of condominium prices bottomed out at the beginning of 2002, while the corresponding repeat sales measure exhibits a reversal only in the spring of 2004. This discrepancy cannot be fully removed even if we apply an age-effect adjustment to the repeat sales index. Section 5 concludes the paper.

\section{Five Measures of Housing Prices}

\subsection{Standard hedonic index}

Let us begin with the hedonic price index. Suppose that we have data for house prices and property characteristics for all periods $t=1,2, \ldots, T$. It is assumed that the price of house $i$ in period $t, P_{i t}$, is given by a Cobb-Douglas function of the lot size of the house, $L_{i}$, and the amount of structures capital in constant quality units, $K_{i t}$ :

$$
P_{i t}=p_{t} L_{i}^{\alpha} K_{i t}^{\beta}
$$

where $p_{t}$ is the quality adjusted house price index, and $\alpha$ and $\beta$ are positive parameters. ${ }^{2}$ It is, moreover, assumed that housing capital is subject to generalized geometric period of time.

${ }^{2}$ McMillen (2003) adopts the same Cobb-Douglas production function for housing services. Thorsnes (1997) describes housing output as a constant elasticity substitution production function of the lot 
depreciation, and that the housing capital in period $t$ is given by

$$
K_{i t}=B_{i} \exp \left(-\delta A_{i t}^{\lambda}\right)
$$

where $B_{i}$ is the floor space of the structure, $A_{i t}$ is the age of the structure in period $t, \delta$ is a parameter between 0 and 1 , and $\lambda$ is a positive parameter. Note that if $\lambda=1,(2)$ reduces to a usual geometric model of depreciation with a constant depreciation rate over time; if $\lambda>1$, the depreciation rate increases with time; if $\lambda<1$, the depreciation rate decreases with time.

By substituting (2) into (1), and taking the logarithm of both sides of the resulting equation, we obtain:

$$
\ln P_{i t}=\ln p_{t}+\alpha \ln L_{i}+\beta \ln B_{i}-\beta \delta A_{i t}^{\lambda}
$$

Adding a vector of attributes of house $i$ other than $L_{i}$ and $K_{i t}$, which is denoted by $x_{i}$, and an error term leads to an estimating equation of the form:

$$
\ln P_{i t}=\alpha \ln L_{i}+\beta \ln B_{i}-\beta \delta A_{i t}^{\lambda}+\gamma^{\prime} x_{i}+d_{t}+v_{i t}
$$

where $\gamma$ is a vector of parameters associated with $x_{i}, d_{t}$ is the coefficient on the time dummy variable representing $\ln p_{t}$, and $v_{i t}$ is an iid normal disturbance.

Running an OLS regression of equation (4) yields estimates for the coefficients on the time dummy variables. After normalizing such that $d_{0}=0$, the series of coefficients on the dummy variables, $d_{2}, \ldots, d_{T}$, is the quality adjusted price index. The standard hedonic price index is then calculated as $I^{H D} \equiv\left\{\exp (0), \exp \left(\hat{d}_{2}\right), \cdots, \exp \left(\hat{d}_{T}\right)\right\}$, where the $\hat{d}$ 's represent the estimated coefficients of the time dummies. Note that the coefficients $\alpha, \beta, \gamma$, and $\delta$ are all identified in this regression.

\subsection{Standard repeat sales index}

The standard repeat sales method starts with the assumption that property characteristics do not change over time and that the parameters associated with these characteristics do not change either. The underlying price determination model is basically the same as in equation (4). However, the repeat sales method focuses on houses that

size and housing capital, and provides some empirical evidence that the elasticity of substitution is close to unity, which implies that the Cobb-Douglas production function is a good approximation of the technology used in the production of housing services. In contrast, Diewert (2009) suggests some possible hedonic regression models that might lead to additive decompositions of an overall property price into land and structures components. Diewert et al. (2010) estimate such an additive hedonic model using the Dutch data. 
appear multiple times in the dataset. Suppose that house $i$ is transacted twice, and that the transactions occur in periods $s$ and $t(s<t)$. Using equation $(4)$, the change in the house price is given by

$$
\Delta_{t, s} \ln P_{i}=\left(d_{t}-d_{s}\right)-\beta \delta\left(A_{i t}^{\lambda}-A_{i s}^{\lambda}\right)+\left(v_{i t}-v_{i s}\right)
$$

Note that the terms that do not include time subscripts in equation (4), namely $\alpha \ln L_{i}$, $\beta \ln B_{i}$, and $\gamma^{\prime} x_{i}$, all disappear by taking differences with respect to time, so that the resulting equation is simpler than the original one. Furthermore, assuming no depreciation of housing capital (i.e. $\delta=0$ ), equation (5) reduces to:

$$
\Delta_{t, s} \ln P_{i}=\left(d_{t}-d_{s}\right)+\left(v_{i t}-v_{i s}\right)
$$

From this equation, we have:

$$
\Delta_{t, s} \ln P_{i}=D_{i}^{\prime} d+\nu_{i t s}
$$

where $\nu_{i t s} \equiv v_{i t}-v_{i s}$ and $D_{i}$ is a time dummy variable vector, which takes a value of 1 at the second transaction, -1 at the first transaction, and 0 in the other periods. Estimates for the coefficients on the time dummies are obtained by running an OLS regression of (7). The standard repeat sales index is then defined by $I^{R S} \equiv$ $\left\{\exp (0), \exp \left(\hat{d}_{2}\right), \cdots, \exp \left(\hat{d}_{T}\right)\right\}$.

\subsection{Case-Shiller adjustment to the repeat sales index}

As pointed out by previous studies, the standard repeat sales index defined above may be biased because (i) the disturbance term in (7) may be heteroscedastic in the sense that the variance of the disturbance term is larger when the two transaction dates are further apart; (ii) the assumption of no depreciation is too restrictive.

Case and Shiller $(1987,1989)$ address the heteroscedasticity problem in the disturbance term by assuming that

$$
E\left(v_{i t}-v_{i s}\right)^{2}=\xi_{1}(t-s)
$$

where $\xi_{1}$ is a positive parameter. The Case-Shiller repeat sales index is estimated as follows. First, equation (7) is estimated, and the resulting squared disturbance term is regressed on the constant term, $\xi_{0}$, and the interval between the two consecutive transactions, namely $t-s$, to obtain estimates for $\xi_{0}$ and $\xi_{1}$. Then, equation (7) is reestimated by GLS with a weight variable of $\left[\hat{\xi}_{0}+\hat{\xi}_{1}(t-s)\right]^{1 / 2}$. Finally, estimates for the coefficients on the time dummies are obtained. The Case-Shiller repeat sales index is defined by $I^{C S} \equiv\left\{\exp (0), \exp \left(\hat{d}_{2}\right), \cdots, \exp \left(\hat{d}_{T}\right)\right\}$. 


\subsection{Age-adjustment to the repeat sales index}

Previous studies on the repeat sales method, including Bailey et al. (1963) and Case and Shiller $(1987,1989)$, do not pay much attention to the possibility that property characteristics change over time. However, there are no houses that do not depreciate, implying that the quality of a house at the time of selling may differ depending on when it is being sold. Also, the quality of a house may change over time because of maintenance and renovation. It may change over time due to changes in the environment surrounding the house, the availability of public transportation, and so on. ${ }^{3}$ As far as the Japanese housing market is concerned, the structure of a house typically depreciates more quickly than in the United States and Europe, which is likely to cause a larger bias in price indexes if house price depreciation is ignored.

To take account of the depreciation effect, we go back to equation (5) and rewrite it as follows:

$$
\Delta_{t, s} \ln P_{i}=\left(d_{t}-d_{s}\right)-\beta \delta\left[\left(A_{i s}+t-s\right)^{\lambda}-A_{i s}^{\lambda}\right]+\nu_{i t s}
$$

Note that repeat sales indexes that do not include an age term - such as the second term on the right-hand side in the equation above - will suffer from a downward bias. ${ }^{4}$

McMillen (2003) considers a simpler version of this model with $\lambda=1$, so that the depreciation rate is constant over time. Then equation (9) reduces to

$$
\Delta_{t, s} \ln P_{i}=\left(d_{t}-d_{s}\right)-\beta \delta(t-s)+\nu_{i t s}
$$

Note that there is exact collinearity between the first and second terms on the right hand side of (10), so that it is impossible to obtain estimates for the coefficients on the time dummies. McMillen (2003) measures the age difference between two consecutive sales in days while using quarterly time dummy variables, thereby eliminating exact collinearity between the time dummies and the age difference.

In this paper we eliminate exact multicollinearity by making use of the functional form of depreciation. ${ }^{5}$ Specifically, we assume that $K_{i t}$ depreciates as described in (2)

\footnotetext{
${ }^{3}$ Note that the depreciation model given by (2) can be regarded as a net depreciation model; i.e., it is depreciation less "normal" renovation and maintenance expenditures. See Diewert (2009) for more on the topic of constructing a house price index taking depreciation and renovation into consideration.

${ }^{4}$ It should be noted that the official S\&P/Case-Shiller home price index is adjusted in the following way to take the age effect into account. Standard \& Poor's (2008: 7) states that "[s]ales pairs are also weighted based on the time interval between the first and second sales. If a sales pair interval is longer, then it is more likely that a house may have experienced physical changes. Sales pairs with longer intervals are, therefore, given less weight than sales pairs with shorter intervals."

${ }^{5}$ See Chau et al. (2005) for an example of adopting a nonlinear specification of the age effect to eliminate multicollinearity between the age variable and the time dummy variables.
} 
instead of assuming a constant depreciation rate over time. In this case, as shown in (9), the time dummies, $d_{t}-d_{s}$, and the age difference, $\left(A_{i s}+t-s\right)^{\lambda}-A_{i s}^{\lambda}$, are not linearly correlated, so that we can discriminate between these two terms.

In constructing the age-adjusted repeat sales index, we run a nonlinear least squares regression for (9) to estimate the coefficients for the time dummies. Note that the parameters $\beta$ and $\delta$ are not identified in this regression because they appear only in the form of $\beta \delta$. This is in sharp contrast with the hedonic regression in (4), in which $\beta$ appears not only as a coefficient of the age term but also as a coefficient on $\ln B_{i}$, so that $\beta$ and $\delta$ are identified.

\subsection{Structural-change adjustment to the hedonic index}

Finally, we modify the standard hedonic model given by equation (4) such that the parameters associated with the attributes of a house are allowed to change over time. Structural changes in the Japanese housing market have two important features. First, they usually occur only gradually, triggered, with a few exceptions, by changes in regulations by the central and local governments. Such gradual changes are quite different from "regime changes" discussed by econometricians such as Bai and Perron (1998) in which structural parameters exhibit a discontinuous shift at multiple times. Second, changes in parameters reflect structural changes at various time frequencies. Specifically, as found by Shimizu et al. (2010), some changes in parameters are associated with seasonal changes in housing market activity. For example, the number of transactions is high at the end of a fiscal year, namely, between January and March, when people move from one place to another due to seasonal reasons such as job transfers, while the number is low during the summer.

One way to allow for gradual shifts in parameters is to employ an adjacent-periods regression, in which equation (4) is estimated using only two periods that are adjacent to each other, thereby minimizing the disadvantage of pooled regressions. For example, Triplett (2004), based on the presumption that coefficients usually change less between two adjacent periods than over more extended intervals, argues that the adjacent-period estimator is "a more benign constraint on the hedonic coefficients." However, as far as seasonal changes in parameters are concerned, this presumption may not necessarily be satisfied, so that adjacent-period regression may not work very well. To cope with this problem, Shimizu et al. (2010) propose a regression method using multiple "neighborhood periods," typically 12 or 24 months, rather than two adjacent periods. Specifically, they estimate parameters by taking a certain length as 
the estimation window and shifting this period as in rolling regressions. This method should be able to handle seasonal changes in parameters better than adjacent-periods regressions, although it may suffer more from the disadvantages associated with pooling.

To apply this method, we estimate equation (4) for $t=1, \ldots, \psi$, where $\psi$ represents the window width. Then we repeat this estimate for the period $[2, \psi+1],[3, \psi+$ $2], \cdots,[T-\psi+1, T]$. This model is referred to as the overlapping-period hedonic housing model (OPHM) by Shimizu et al. (2010). Note that this procedure reduces to an adjacent-periods regression for $\psi=2$. Each of the regressions with a window of $\psi$ provides estimates of the parameters associated with the time dummies.

\section{Data}

\subsection{Overview}

We collect housing prices from a weekly magazine, Shukan Jutaku Joho (Residential Information Weekly), published by Recruit Co., Ltd., one of the largest vendors of residential lettings information in Japan. The Recruit dataset covers the 23 special wards of Tokyo for the period 1986 to 2008, which includes the bubble period in the late 1980s and its collapse in the early 1990s. It contains 157,627 listings for condominiums and 315,791 listings for single family houses, for 473,418 listings in total. ${ }^{6}$ Shukan Jutaku Joho provides time series of the price of a unit from the week it is first posted until the week it is removed because of successful transaction. ${ }^{7}$ We only use the price in the final week because this can be safely regarded as sufficiently close to the contract price. $^{8}$

\subsection{Variables}

Table 1 shows a list of the attributes of a house. Key attributes include the ground area $(G A)$, floor space $(F S)$, and front road width $(R W)$. The ground area is available in the

\footnotetext{
${ }^{6}$ Shimizu et al. (2004) report that the Recruit data cover more than 95 percent of the entire transactions in the 23 special wards of Tokyo. On the other hand, its coverage for suburban areas is very limited. We therefore use only information for the units located in the special wards of Tokyo.

${ }^{7}$ There are two reasons for the listing of a unit being removed from the magazine: a successful deal or a withdrawal (i.e., the seller gives up looking for a buyer and thus withdraws the listing). We were allowed to access information regarding which of the two reasons applied for individual cases and discarded those where the seller withdrew the listing.

${ }^{8}$ Recruit Co., Ltd., provided us with information on contract prices for about 24 percent of the entire listings. Using this information, we were able to confirm that prices in the final week were almost always identical to the contract prices (i.e., they differed at a probability of less than 0.1 percent).
} 
original dataset for single family houses but not for condominiums, so we estimate the latter by dividing the land area of a structure by the number of units in the structure. ${ }^{9}$ The age of a house is defined as the number of quarters between the date of the construction of the house and the transaction. We construct a dummy (south-facing dummy, $S D$ ) to indicate whether the windows of a house are south-facing or not (note that the Japanese are particularly fond of sunshine). The private road dummy, $P D$, indicates whether a house has an adjacent private road or not. The land-only dummy, $L D$, indicates whether a transaction is only for land without a building or not. The convenience of public transportation from a house is represented by the travel time to the central business district $(\mathrm{CBD}),{ }^{10}$ which is denoted by $T T$, and the time to the nearest station, ${ }^{11}$ which is denoted by $T S$. We use a ward dummy, WD, to indicate differences in the quality of public services available in each district, and a railway line dummy, $R D$, to indicate along which railway/subway line a house is located.

\subsection{The hedonic sample versus the repeat sales sample}

Table 2 compares the sample used in the hedonic regressions and the sample used in the repeat sales regressions. Since repeat sales regressions use only observations from houses that are traded multiple times, the repeat sales sample is a subset of the hedonic sample. The ratio of the repeat sales sample to the hedonic sample is 42.7 percent for condominiums and 6.1 percent for single family houses, indicating that single family houses are less likely to appear multiple times on the market.

The average price for condominiums is 38 million yen in the hedonic sample, while it is 44 million yen in the repeat sales sample. On the other hand, the average price for single family houses is 79 million yen in the hedonic sample and 76 million yen in the repeat sales sample. Turning to house attributes, houses in the repeat sales sample

\footnotetext{
${ }^{9}$ More specifically, the land area of a structure is calculated by dividing the sum of the floor space for each unit in the structure by FAR $\times$ BLR, where FAR and BLR stand for the floor area ratio and the building to land ratio, respectively. The sum of the floor space of each unit in a structure is available in the original dataset. The maximum values for FAR and BLR are subject to regulation under city planning law. We assume that this regulation is binding.

${ }^{10}$ Travel time to the CBD is measured as follows. The metropolitan area of Tokyo is composed of 23 wards and contains a dense railway network. Within this area, we choose seven railway/subway stations as central business district stations: Tokyo, Shinagawa, Shibuya, Shinjuku, Ikebukuro, Ueno, and Otemachi. We then define travel time to the CBD as the minutes needed to commute to the nearest of the seven stations in the daytime.

${ }^{11}$ The time to the nearest station, TS, is defined as the walking time to the nearest station if a house is located within walking distance from a station, and the sum of the walking time to a bus stop and the bus travel time from the bus stop to the nearest station if a house is located in a bus transportation area. We use a bus dummy, $B D$, to indicate whether a house is located in walking distance from a railway station or in a bus transportation area.
} 
tend to be larger in terms of the floor space, and more conveniently located in terms of time to the nearest station and travel time to a central business district, although these differences are not statistically significant. An important and statistically significant difference between the two samples is the average age of units in the case of single family houses; namely, the repeat sales sample consists of houses that are constructed relatively recently. Somewhat interestingly, single family houses in the repeat sales sample are larger in terms of floor space, more conveniently located, more recently constructed, but are less expensive.

\section{Estimation Results}

\subsection{Age effects}

Table 3 presents the regression results for the standard hedonic model given by equation (4). The model fits well both for condominiums and single family houses: the adjusted R-squared is 0.882 for condominiums and 0.822 for single family houses. The coefficients of interest are the ones associated with the age effect. The estimates of $\delta$ and $\lambda$ are 0.033 and 0.691 for condominiums, implying that the initial capital stock of structures declines to 0.457 after 100 quarters, and that the average annual geometric depreciation rate for 100 quarters is 0.031 . On the other hand, the estimates of $\delta$ and $\lambda$ for single family houses are 0.020 and 0.688 , implying that the initial capital stock of structures declines to 0.619 after 100 quarters, and that the average annual depreciation rate for 100 quarters is 0.019 .

Table 4 presents the regression results for the age-adjusted repeat sales model given by equation (9). We see that the estimates of $\beta \delta$ and $\lambda$ are 0.0098 and 0.894 for condominiums, and 0.002 and 1.104 for single family houses. Note that the repeat sales regressions do not allow us to estimate $\beta$ and $\delta$ separately. If we borrow estimates of $\beta$ from the hedonic regressions, the value of $\delta$ turns out to be 0.019 for condominiums and 0.004 for single family houses. These estimates imply that the average annual rate of depreciation for 100 quarters is 0.045 for condominiums and 0.025 for single family houses. Figure 1 compares the hedonic and repeat sales regressions in terms of the estimated age effect. We see that the estimates from the repeat sales regressions indicate slightly faster depreciation than the ones from the hedonic regressions both for condominiums and for single family houses, although the difference is not very large.

Next, we turn to the bottom panel of Table 4, which looks at the regression performance of the three types of repeat sales measures: the standard repeat sales index, 
the heteroscedasticity-adjusted repeat sales index (i.e., the Case-Shiller index), and the age-adjusted repeat sales index. We see that the age-adjusted repeat sales index performs better than the standard one both for condominiums and single family houses. On the other hand, we fail to find a significant difference between the age-adjusted index and the Case-Shiller index.

\subsection{Structural change adjustment to the standard hedonic measure}

To eliminate any measurement error due to shifts in the parameters in the standard hedonic model, we estimate equation (4) by rolling regression, which allows gradual shifts in the parameters. Specifically, we set the width of the rolling regression as $\psi=12$ (i.e., a 12-month rolling regression). The result is presented in Table 5, which compares key parameters of the standard hedonic model and the rolling hedonic model. For condominiums, we see that the average value of each parameter estimated by the rolling hedonic regression is close to the estimate obtained by the standard hedonic regression. For example, the parameter associated with the floor space of a house is 0.528 using the standard hedonic regression, while the average value of the corresponding parameters estimated by the rolling regression is 0.517 . More importantly, we find that the estimated parameters fluctuate considerably during the sample period. For example, the parameter associated with the floor space of a house fluctuates between 0.508 and 0.539 , indicating that non-negligible structural changes occur during the sample period. We see the same regularities for single family houses.

\subsection{To what extent can the differences be reconciled?}

As we stated in Section 1, the standard hedonic measure may be biased either because of omitted variables or because of shifts in structural parameters. We have solved the latter problem, at least partially, by allowing the parameters of the hedonic regression to change over time. On the other hand, the standard repeat sales measure faces the problems of non-random sampling and changes in the attributes of a house, such as its age. We have removed part of the latter problem by introducing an age adjustment to the repeat sales measure. We now proceed to examine to what extent the differences between the hedonic and repeat sales measures have been reconciled through these adjustments. 


\subsubsection{Graphic comparison of the five indexes}

As a first step, we conduct a graphic comparison of the five indexes. Figure 2a shows the estimated five indexes for condominiums. The age-adjusted repeat sales index starts in the fourth quarter of 1989, while the other four indexes start in the first quarter of 1986. To make the comparison easier, the indexes are normalized so that they are all equal to unity in the fourth quarter of 1989. The first thing we can see from this figure is that there is almost no difference between the standard repeat sales index and the CaseShiller repeat sales index. This suggests that heteroscedasticity due to heterogeneous transaction intervals may not be very important as far as the Japanese housing market is concerned. Second, the age-adjusted repeat sales index behaves differently from the other two repeat sales indexes. Specifically, it exhibits a less rapid decline in the 1990s, i.e., the period when the bubble burst. This difference reflects the relative importance of the age effect, implying that the other two repeat sales indexes, which pay no attention to the age effect, tend to overestimate the magnitude of the burst of the bubble. Third, the two hedonic indexes exhibit a less rapid decline in the 1990s than the standard and the Case-Shiller repeat sales indexes, and the discrepancy between them tends to increase over time in the rest of the sample period.

Figure $2 \mathrm{~b}$ show the estimated indexes for single family houses. We see that the three repeat sales indexes and the standard hedonic index tend to move together, but the rolling hedonic index behaves differently from them. The spread between the rolling hedonic index and the other four indexes tends to expand gradually in the latter half of the 1990s, suggesting the presence of some gradual shifts in the structural parameters during this period.

\subsubsection{The contemporaneous correlation between the five indexes}

Next, we compare the five indexes for condominiums in terms of their quarterly growth rates. The results are presented in Figure 3. The horizontal axis in the upper left panel represents the growth rate of the standard repeat sales index, while the vertical axis represents the growth rate of the Case-Shiller repeat sales index. One can clearly see that almost all dots in this panel are exactly on the 45 degree line, implying that these two indexes are closely correlated with each other. In fact, the coefficient of correlation is 0.995 at the quarterly frequency, and 0.974 at the monthly frequency. If we regress the quarterly growth rate of the Case-Shiller repeat sales index, denoted by $y$, on that of the standard repeat sales index, denoted by $x$, we obtain $y=0.9439 x-0.0002$, indicating that the coefficient on $x$ and the constant term are very close to unity 
and zero, respectively. Similarly, the lower left panel compares the growth rate of the standard repeat sales index and the age-adjusted repeat sales index. Again, almost all dots are on the 45 degree line, indicating a high correlation between the two indexes (the coefficient of correlation is 0.991 at the quarterly frequency and 0.953 at the monthly frequency). However, the regression result shows that the constant term is slightly above zero, indicating that the growth rates for the age-adjusted repeat sales index are, on average, slightly higher than those for the standard repeat sales index.

Turning to the upper right panel, which compares the standard hedonic index and the standard repeat sales index, the dots are again scattered along the 45 degree line but not exactly on it, indicating a lower correlation than before ( 0.845 at the quarterly frequency and 0.458 at the monthly frequency). More importantly, we obtain $y=1.0948 x+0.0036$ by regressing the standard hedonic index on the standard repeat sales index, and the constant term is positive and significantly different from zero. In other words, the standard hedonic index tends to grow faster than the standard repeat sales index, which is consistent with what we saw in Figure 2a. ${ }^{12}$ Finally, the lower right panel compares the standard repeat sales index and the rolling hedonic index, showing that the two indexes are even more weakly correlated (0.773 at the quarterly frequency and 0.444 at the monthly frequency), and that the rolling hedonic index tends to grow faster than the standard repeat sales index.

To examine the contemporaneous relationship in a different manner, we regress the quarterly growth rate of one of the five indexes, say index A, on the quarterly growth rate of another index, say index B, to obtain a simple linear relationship $y=a+b x$. Then we conduct an F-test against the null hypothesis that $a=0$ and $b=1$. The results of this exercise are presented in Table 6 , in which the number in each cell represents the p-value associated with the null hypothesis that $a=0$ and $b=1$ in a regression in which the index in the corresponding row is the dependent variable while the index in the corresponding column is the independent variable. For example, the number in the lower left corner of the upper panel, 0.0221, represents the p-value associated with the null hypothesis in the regression in which the growth rate of the rolling hedonic index is the dependent variable and the growth rate of the standard repeat sales index is the independent variable. The upper panel, which presents the results for condominiums,

\footnotetext{
${ }^{12}$ We see from the upper right panel of Figure 3 that several dots in the right upper quadrant are well above the 45 degree line, indicating that the growth rates of the standard hedonic index are substantially higher than those of the standard repeat sales index at least for these quarters. These dots correspond to the quarters between 1986 and 1987, during which the standard hedonic index exhibits much more rapid growth than the standard repeat sales index, as we saw in Figure 2a.
} 
shows that in almost all cases the null hypothesis cannot be rejected. However, there are two cases in which the p-value exceeds 10 percent: when the standard hedonic index is regressed on the age-adjusted repeat sales index ( $\mathrm{p}$-value $=0.2120)$, and when the rolling hedonic index is regressed on the standard hedonic index ( $\mathrm{p}$-value $=0.1208$ ).

Looking at the lower panel of Table 6 , which presents the results for single family houses, we see that there are more cases in which the null hypothesis is rejected. For example, the p-value is very high at 0.7661 when the standard hedonic index is regressed on the standard repeat sales index, so that we easily reject the null that the hedonic and the repeat sales indexes are close to each other.

\subsubsection{The dynamic relationship between the five indexes}

The presence of a close contemporaneous correlation in terms of quarterly growth rates between the five indexes does not immediately imply that the five indexes perfectly move together. It is still possible that there exist some lead-lag relationships between the five indexes; for example, one index may tend to precede the other four indexes. To investigate such dynamic relationships between the five indexes, we conduct pairwise Granger causality tests. The results for condominiums and single family houses are presented, respectively, in the upper and lower panels of Table 7. The number in each cell represents the p-value associated with the null hypothesis that the index in a particular row does not Granger-cause the index in the column. For example, the number in the cell in the third row and second column, 0.2018, represents the p-value associated with the null hypothesis that the Case-Shiller type repeat sales index does not cause the standard repeat sales index. The panel for condominiums shows that one can easily reject the null that the standard hedonic index does not cause the other four indexes. On the other hand, one cannot reject the null that each of the other four indexes does not cause the standard hedonic index. These two results indicate that fluctuations in the standard hedonic index tend to precede those in the other four indexes. The same property is observed for single family houses.

To illustrate such lead-lag relationships between the five indexes, we compare them in terms of the timing in which each index bottomed out after the bursting of the housing bubble in the early 1990s. The result for condominiums is presented in Figure 4. We see that all of the three repeat sales indexes bottom out simultaneously in the first quarter of 2004. In contrast, the two hedonic indexes bottom out in the first quarter of 2002, indicating that the turn in the hedonic indexes preceded the one in the repeat sales indexes by two years. 
An important issue we need to address is where such lead-lag relationships between the hedonic and repeat sales indexes come from. There are at least two possibilities. First, the presence of the lead-lag relationships may be related to the omitted variable problem in hedonic regressions. It is possible that the variables omitted in hedonic regressions move only with some lags relative to the other variables, leading to an excessively quick response of the estimated hedonic indexes to various shocks. The second possibility is related to sample selection bias in the estimated repeat sales indexes. As we saw in Table 2, the sample employed for producing the repeat sales index makes up only a very limited fraction of the total numbers of observations and, more importantly, might be biased in that it consists of houses whose prices exhibit a delayed response to various shocks.

How can we discriminate between these two possibilities? One way to identify the reason behind the relationships is to apply the hedonic regressions to the repeat sales sample (i.e., the sample consisting of houses that are traded multiple times). The new hedonic index produced in this way and the standard hedonic index differ in terms of the sample employed but otherwise are identical in terms of the explanatory variables used, so that they suffer from the same omitted variables problem. Therefore, any remaining differences between the new and the standard hedonic index can be regarded as stemming from the difference in the sample employed. If we still observe a lead-lag relationship between the new and the standard hedonic index, this would imply that this lead-lag relationship is due to the sample selection bias in the repeat sales indexes.

Figure 5 presents the result of this exercise. We apply the hedonic regressions to four different samples: a sample of houses that were traded at least once (i.e., the entire sample); a sample of houses that were traded more than once (i.e., the original repeat sales sample); a sample of houses that were traded more than twice; and a sample of houses that were traded more than three times. We find that the indexes using the samples of houses that were traded more than once ("traded more than once," "traded more than twice," and "traded more than three times") exhibit a later turn than the index estimated from the larger sample of houses that were "traded at least once," suggesting that the lead-lag relationships between the hedonic and repeat sales indexes in Figure 4 mainly come from sample selection bias in the repeat sales indexes. Moreover, consistent with this interpretation, the delay in the turning point becomes even more pronounced when using the samples of houses "traded more than twice" and "traded more than three times." 


\section{Conclusion}

Do indexes of house prices behave differently depending on the estimation method? And if so, to what extent? To address these questions, we estimated five house price indexes, consisting of two kinds of hedonic indexes and three kinds of repeat sales indexes, using a unique dataset we compiled from individual listings in a widely circulated real estate advertisement magazine.

We found no substantial difference between the five indexes in terms of contemporaneous correlation. However, we found significant differences between the five indexes in terms of their dynamic relationship. Specifically, we found that there exists a substantial discrepancy in terms of turning points between the hedonic and repeat sales indexes even when the hedonic index is adjusted for structural changes and the repeat sales index is adjusted in the way Case and Shiller suggested. The repeat sales measure tends to exhibit a delayed turn compared with the hedonic measure; for example, the hedonic measure of condominium prices bottomed out at the beginning of 2002, while the corresponding repeat sales measure exhibits a reversal only in the spring of 2004 .

The quality of a house changes more rapidly over time in Japan because of the short lifespan of houses. To cope with this problem, we provided a generalization of the repeat sales model which takes into account the aging of the structure between the repeat sales, and applied it to the Japanese data. We found that the new method provides more reliable estimates, but the discrepancy between the five indexes in terms of turning points cannot be fully removed even if we adjust the repeat sales index for depreciation. We provide empirical evidence suggesting that the difference between the hedonic and repeat sales indexes mainly comes from non-randomness in the repeat sales sample.

\section{References}

[1] Bai, J., and P. Perron (1998), "Estimating and Testing Linear Models with Multiple Structural Changes," Econometrica 66, 47-78.

[2] Bailey, M.J., R.F. Muth, and H.O. Nourse (1963), "A Regression Model for Real Estate Price Index Construction," Journal of the American Statistical Association 58, 933-942.

[3] Bourassa, S.T., M. Hoesli, and J. Sun (2006), "A Simple Alternative House Price Index Method," Journal of Housing Economics 15, 80-97. 
[4] Case, B., H.O. Pollakowski, and S.M. Wachter (1991), "On Choosing Among House Price Index Methodologies," AREUEA Journal 19, 286-307.

[5] Case, B., and J.M. Quigley (1991), "The Dynamics of Real Estate Prices," Review of Economics and Statistics 22, 50-58.

[6] Case, K.E., and R.J. Shiller (1987), "Prices of Single Family Homes Since 1970: New Indexes for Four Cities," New England Economic Review Sept./Oct., 45-56.

[7] Case, K.E., and R.J. Shiller (1989), "The Efficiency of the Market for Single Family Homes," American Economic Review 79, 125-137.

[8] Chau, K.W., S.K. Wong, and C.Y. Yiu (2005), "Adjusting for Non-Linear Age Effects in the Repeat Sales Index," Journal of Real Estate Finance and Economics 31, 137-153.

[9] Clapp, J.M., and C. Giaccotto (1992), "Estimating Price Trends for Residential Property: A Comparison of Repeat Sales and Assessed Value Methods," Journal of Real Estate Finance and Economics 5, 357-374.

[10] Clapp, J.M., and C. Giaccotto (1998), "Price Indexes Based on the Hedonic Repeat-Sales Method: Application to the Housing Market," Journal of Real Estate Finance and Economics 16, 5-26.

[11] Diewert, W.E. (2009), "The Paris OECD-IMF Workshop on Real Estate Price Indexes: Conclusions and Future Directions," in Price and Productivity Measurement: Volume 1 - Housing, Trafford Press, 87-116.

[12] Diewert, W.E., J. de Haan and R. Hendriks (2010), "The Decomposition of a House Price Index into Land and Structures Components: A Hedonic Regression Approach," Discussion Paper 10-01, Department of Economics, University of British Columbia.

[13] Ekeland, I., J.J. Heckman, and L. Nesheim (2004), "Identification and Estimation of Hedonic Models," Journal of Political Economy 112, 60-109.

[14] Goodman, A.C., and T.G. Thibodeau (1998), "Dwelling Age Heteroskedasticity in Repeat Sales House Price Equations," Real Estate Economics 26, 151-171.

[15] McMillen, D.P. (2003), "The Return of Centralization to Chicago: Using Repeat Sales to Identify Changes in House Price Distance Gradients," Regional Science and Urban Economics 33, 287-304.

[16] Shimizu, C., K.G. Nishimura, and Y. Asami (2004), "Search and Vacancy Costs in the Tokyo Housing Market: An Attempt to Measure Social Costs of Imperfect Information," Review of Urban and Regional Development Studies 16, 210-230. 
[17] Shimizu, C., and K.G. Nishimura (2006), "Biases in Appraisal Land Price Information: The Case of Japan," Journal of Property Investment and Finance 26, $150-175$

[18] Shimizu, C., and K.G. Nishimura (2007), "Pricing Structure in Tokyo Metropolitan Land Markets and Its Structural Changes: Pre-Bubble, Bubble, and PostBubble Periods," Journal of Real Estate Finance and Economics 35, 475-496.

[19] Shimizu, C., H. Takatsuji, H. Ono, and K.G. Nishimura (2010), "Structural and Temporal Changes in the Housing Market and Hedonic Housing Price Indices: The Case of the Previously Owned Condominium Market in the Tokyo Metropolitan Area," International Journal of Housing Markets and Analysis 3, forthcoming.

[20] Standard \& Poor's (2008), S\&P/Case-Shiller Home Price Indexes: Index Methodology, March 2008. Available at http://www2.standardandpoors.com/spf/pdf/ index/SP_CS_Home_Price_indexes_Methodology_Web.pdf

[21] Thorsnes, P. (1997), "Consistent Estimates of the Elasticity of Substitution between Land and Non-Land Inputs in the Production of Housing," Journal of Urban Economics 42, 98-108.

[22] Triplett, J. (2004), Handbook on Hedonic Indexes and Quality Adjustments in Price Indexes, OECD Science, Technology and Industry Working Papers 2004/9. 


\section{Table 1: List of variables}

\begin{tabular}{|c|c|c|c|}
\hline Abbreviation & Variable & Des cription & Unit \\
\hline GA & Ground area & Ground area. & $\mathrm{m}^{2}$ \\
\hline FS & Floor space & Floor space of building. & $\mathrm{m}^{2}$ \\
\hline$R W$ & Front road width & Front road width. & $10 \mathrm{~cm}$ \\
\hline$A G E$ & $\begin{array}{c}\text { Age of building at the time of } \\
\text { transaction }\end{array}$ & Age of building at the time of transaction. & Quarters \\
\hline TS & Time to the nearest station & Time distance to the nearest station (walking time or time by bus or car). & Minutes \\
\hline$T T$ & $\begin{array}{c}\text { Travel time to central business } \\
\text { district }\end{array}$ & $\begin{array}{l}\text { Minimum railway riding time in daytime to one of the seven major } \\
\text { business district stations. }\end{array}$ & Minutes \\
\hline$U V$ & Unit volume & Unit volume/The total number of units of a condominium. & Unit \\
\hline$R T$ & Market reservation time & $\begin{array}{l}\text { Period between the date when the data appear in the magazine for the } \\
\text { first time and the date of being deleted. }\end{array}$ & Weeks \\
\hline \multirow{2}{*}{$B D$} & \multirow{2}{*}{ Bus dummy } & \begin{tabular}{|l|l} 
Time distance to the nearest station includes taking the bus $=1$ \\
\end{tabular} & \multirow{2}{*}{$(0,1)$} \\
\hline & & Does not include taking the bus $=0$. & \\
\hline \multirow{2}{*}{$C D$} & \multirow{2}{*}{ Car dummy } & Time distance to the nearest station includes taking the car $=1$. & \multirow{2}{*}{$(0,1)$} \\
\hline & & Does not include taking the car $=0$. & \\
\hline \multirow{2}{*}{$F D$} & \multirow{2}{*}{ First floor dummy } & The property is on the ground floor $=1$. & \multirow{2}{*}{$(0,1)$} \\
\hline & & The property is not on the ground floor $=0$. & \\
\hline \multirow[t]{2}{*}{$B B D$} & \multirow{2}{*}{$\begin{array}{l}\text { Before new building standard } \\
\text { law dummy }\end{array}$} & $\begin{array}{l}\text { Construction year is before } 1981 \text { (when the new building standard law was } \\
\text { enacted)* }=1 \text {. }\end{array}$ & \multirow[t]{2}{*}{$(0,1)$} \\
\hline & & Construction year is in or after $1981=0$ & \\
\hline \multirow{2}{*}{$S R C$} & \multirow{2}{*}{$\begin{array}{l}\text { Steel reinforced concrete } \\
\text { dummy }\end{array}$} & Steel reinforced concrete frame structure $=1$. & \multirow{2}{*}{$(0,1)$} \\
\hline & & Other structure $=0$. & \\
\hline \multirow{2}{*}{$S D$} & \multirow{2}{*}{ South-facing dummy } & Main windows facing south $=1$. & \multirow{2}{*}{$(0,1)$} \\
\hline & & Main windows facing not facing south $=0$. & \\
\hline \multirow{2}{*}{$P D$} & \multirow{2}{*}{ Private road dummy } & Site includes part of private road $* *=1$ & \multirow{2}{*}{$(0,1)$} \\
\hline & & Site does not include any part of private road $=0$. & \\
\hline \multirow{2}{*}{$L D$} & \multirow{2}{*}{ Land only dummy } & The transaction includes land only (no building is on the site) $=1$. & \multirow{2}{*}{$(0,1)$} \\
\hline & & The transaction includes land and building $=0$. & \\
\hline \multirow[b]{2}{*}{$O D$} & \multirow[b]{2}{*}{ Old house dummy*** } & The transaction includes an existing building which cannot be used $=1$. & \multirow[b]{2}{*}{$(0,1)$} \\
\hline & & $\begin{array}{l}\text { The transaction does not include an existing building which cannot be } \\
\text { used }=0 \text {. }\end{array}$ & \\
\hline$B A$ & Balcony area & \begin{tabular}{|l|} 
Balcony area. \\
\end{tabular} & $\mathrm{m}^{2}$ \\
\hline$B L R$ & Building-to-land ratio & Building-to-land ratio regulated by City Planning Law. & $\%$ \\
\hline FAR & Floor area ratio & Floor area ratio regulated by City Planning Law. & $\%$ \\
\hline \multirow{2}{*}{$W D k(k=0, \ldots, K)$} & \multirow{2}{*}{ Ward dummies } & Located in ward $k=1$ & $(01)$ \\
\hline & & Located in other ward $=0$. & $(0,1)$ \\
\hline$R D I(l=0 \quad I)$ & Railway line dummies & Located on railway line $l=1$. & $(01)$ \\
\hline 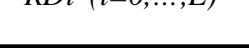 & 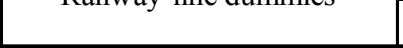 & Located on other railway line $=0$. & $(0,1)$ \\
\hline$T D m(m=0 \quad M)$ & Time dummies (monthly) & Month $m=1$ & $(01)$ \\
\hline $1 D M(m-0, \ldots, N)$ & 1 & Other month $=0$ & $(0,1)$ \\
\hline
\end{tabular}

* The new building standard law established earthquake-resistance standards.

** The building standard law prohibits the construction of a building if the site faces a road which is narrower than 2 meters. If the site does not face a road which is wider than 2 meters, the site must provide a part of its own site as a part of the road.

$* * *$ If there is an existing building which cannot be used, the buyer has to pay the demolition costs. 
Table 2: Hedonic vs. repeat sales samples

Condominiums

Variable

$$
\text { Repeat sales sample }
$$

Hedonic sample

Repeat sales sample

\begin{tabular}{|c|c|c|c|c|}
\hline Average price $(10,000$ yen $)$ & $\begin{array}{c}3,862.26 \\
(3,190.83)\end{array}$ & $\begin{array}{c}4,463.43 \\
(4,284.10)\end{array}$ & $\begin{array}{c}7,950.65 \\
(8,275.04)\end{array}$ & $\begin{array}{c}7,635.24 \\
(7,055.96)\end{array}$ \\
\hline FS: Floor space $\left(\mathrm{m}^{2}\right)$ & $\begin{array}{l}58.31 \\
(21.47)\end{array}$ & $\begin{array}{c}59.54 \\
(24.09)\end{array}$ & $\begin{array}{l}102.53 \\
(43.47)\end{array}$ & $\begin{array}{l}105.82 \\
(45.60)\end{array}$ \\
\hline GA: Ground area $\left(\mathrm{m}^{2}\right)$ & $\begin{array}{c}23.39 \\
(12.79)\end{array}$ & $\begin{array}{c}20.53 \\
(11.97)\end{array}$ & $\begin{array}{l}108.20 \\
(71.19)\end{array}$ & $\begin{array}{l}101.41 \\
(63.17)\end{array}$ \\
\hline $\begin{array}{l}\text { Age: Age of building } \\
\text { (quarters) }\end{array}$ & $\begin{array}{c}55.61 \\
(33.96)\end{array}$ & $\begin{array}{l}60.07 \\
(34.05)\end{array}$ & $\begin{array}{c}54.06 \\
(32.28)\end{array}$ & $\begin{array}{c}21.26 \\
(30.88)\end{array}$ \\
\hline $\begin{array}{l}\text { TS: Time to the nearest station } \\
\text { (minutes) }\end{array}$ & $\begin{array}{c}7.96 \\
(4.43)\end{array}$ & $\begin{array}{c}7.77 \\
(4.28)\end{array}$ & $\begin{array}{c}9.85 \\
(4.54)\end{array}$ & $\begin{array}{c}9.60 \\
(4.37)\end{array}$ \\
\hline $\begin{array}{l}T T \text { : Travel time to central } \\
\text { business district (minutes) }\end{array}$ & $\begin{array}{l}12.58 \\
(7.09)\end{array}$ & $\begin{array}{l}10.73 \\
(6.88)\end{array}$ & $\begin{array}{l}13.23 \\
(6.34)\end{array}$ & $\begin{array}{l}11.89 \\
(6.18)\end{array}$ \\
\hline & $\mathrm{n}=157,627$ & $\mathrm{n}=67,436$ & $\mathrm{n}=315,791$ & $\mathrm{n}=19,428$ \\
\hline
\end{tabular}




\section{Table 3: Hedonic regressions}

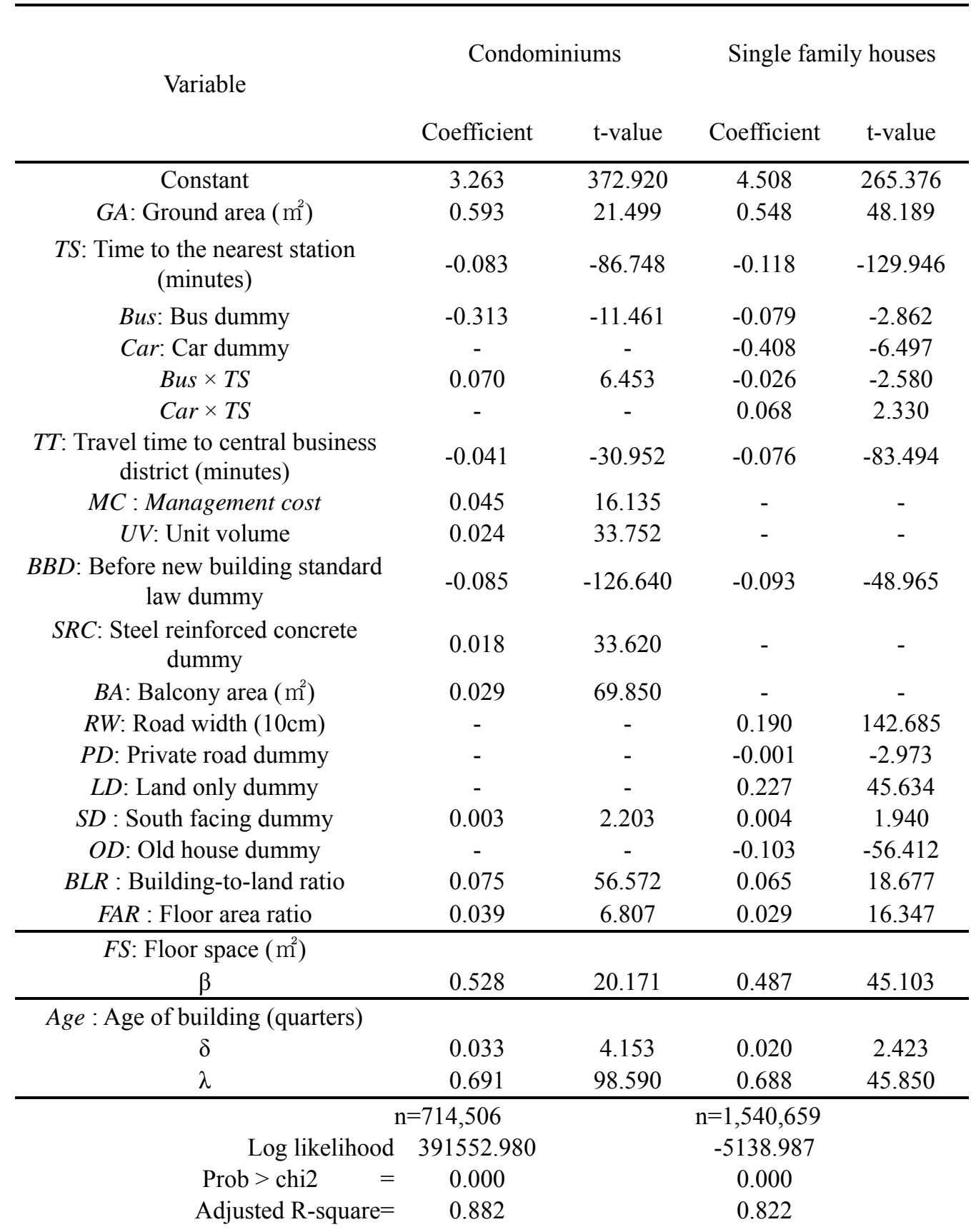

Note: The dependent variable in each case is the log of the price. 
Table 4: Age-adjusted repeat sales regressions

\begin{tabular}{|c|c|c|c|c|}
\hline & & & & \\
\hline & & $\beta \delta$ & $\lambda$ & \\
\hline & \multicolumn{3}{|l|}{ Condominiums } & \\
\hline & Coef. & 0.0098 & 0.8944 & \\
\hline & Std. err. & 0.0004 & 0.0113 & \\
\hline & p-value & {$[.000]$} & {$[.000]$} & \\
\hline & \multicolumn{3}{|l|}{ Single family houses } & \\
\hline & Coef. & 0.0019 & 1.1041 & \\
\hline & Std. err. & 0.0002 & 0.0269 & \\
\hline & p-value & {$[.000]$} & {$[.000]$} & \\
\hline & & $\begin{array}{c}\text { Standard error } \\
\text { of reg. }\end{array}$ & $\begin{array}{l}\text { Adjusted } \\
\text { R-squared }\end{array}$ & S.B.I.C. \\
\hline \multicolumn{5}{|l|}{ Condominiums } \\
\hline \multicolumn{2}{|c|}{ Standard repeat sales } & 0.175 & 0.751 & -20311.0 \\
\hline \multicolumn{2}{|c|}{ Case-Shiller repeat sales } & 0.191 & 0.760 & -12925.4 \\
\hline \multicolumn{2}{|c|}{ Age-adjusted repeat sales } & 0.190 & 0.761 & -13246.6 \\
\hline \multicolumn{5}{|l|}{ Single Family Houses } \\
\hline \multicolumn{2}{|c|}{ Standard repeat sales } & 0.211 & 0.478 & -2087.0 \\
\hline \multicolumn{2}{|c|}{ Case-Shiller repeat sales } & 0.218 & 0.511 & -1136.1 \\
\hline \multicolumn{2}{|c|}{ Age-adjusted repeat sales } & 0.218 & 0.513 & -1176.4 \\
\hline
\end{tabular}

S.B.I.C.: Schwarz's Bayesian information criterion 
Table 5: Standard vs. rolling regressions

\begin{tabular}{|c|c|c|c|c|c|c|c|}
\hline & Constant & $\begin{array}{c}\text { FS: Floor } \\
\text { space }\end{array}$ & $\begin{array}{c}\text { GA: } \\
\text { Ground } \\
\text { area }\end{array}$ & Age: Ag & building & $\begin{array}{l}\text { TS: Time } \\
\text { to the } \\
\text { nearest } \\
\text { station }\end{array}$ & $\begin{array}{c}\text { TT: Travel } \\
\text { time to central } \\
\text { business } \\
\text { district }\end{array}$ \\
\hline \multicolumn{8}{|l|}{ Condominium prices } \\
\hline Standard hedonic model & 3.263 & 0.528 & 0.593 & 0.017 & 0.691 & -0.083 & -0.041 \\
\hline \multicolumn{8}{|l|}{ 12-month rolling regression } \\
\hline Average & 3.200 & 0.517 & 0.608 & 0.016 & 0.690 & -0.082 & -0.042 \\
\hline Standard deviation & 0.086 & 0.079 & 0.040 & 0.001 & 0.035 & 0.015 & 0.013 \\
\hline Minimum & 2.988 & 0.508 & 0.562 & 0.019 & 0.654 & -0.097 & -0.069 \\
\hline Maximum & 3.429 & 0.539 & 0.613 & 0.011 & 0.710 & -0.051 & -0.025 \\
\hline \multicolumn{8}{|l|}{ Single family house prices } \\
\hline Standard hedonic model & 4.508 & 0.487 & 0.548 & 0.010 & 0.688 & -0.118 & -0.076 \\
\hline \multicolumn{8}{|l|}{ 12-month rolling regression } \\
\hline Average & 4.691 & 0.485 & 0.532 & 0.006 & 0.681 & -0.101 & -0.079 \\
\hline Standard deviation & 0.176 & 0.021 & 0.098 & 0.001 & 0.029 & 0.003 & 0.002 \\
\hline Minimum & 4.496 & 0.480 & 0.512 & 0.007 & 0.670 & -0.110 & -0.079 \\
\hline Maximum & 4.742 & 0.495 & 0.558 & 0.006 & 0.700 & -0.041 & -0.048 \\
\hline
\end{tabular}

Number of models $=265$ 


\section{Table 6: Contemporaneous relationship between the five measures}

Condominiums

\begin{tabular}{|c|c|c|c|c|c|}
\hline & $\begin{array}{c}\text { Standard repeat } \\
\text { sales }\end{array}$ & $\begin{array}{c}\text { Case-Shiller repeat } \\
\text { sales }\end{array}$ & $\begin{array}{c}\text { Age-adjusted } \\
\text { repeat sales }\end{array}$ & Standard hedonic & Rolling hedonic \\
\hline Standard repeat sales & 0.0001 & 0.0015 & 0.0001 & 0.0001 \\
\hline Case-Shiller RS & 0.0001 & 0.0001 & 0.0001 & 0.0001 \\
\hline Age-adjusted RS & 0.0121 & 0.0028 & 0.2120 & 0.0216 & 0.0058 \\
\hline Standard hedonic & 0.0221 & 0.0408 & 0.0001 & 0.0057 \\
\hline Rolling hedonic & & & & & 0.1208 \\
\hline
\end{tabular}

Single family houses

\begin{tabular}{|c|c|c|c|c|c|}
\hline & $\begin{array}{c}\text { Standard repeat } \\
\text { sales }\end{array}$ & $\begin{array}{c}\text { Case-Shiller repeat } \\
\text { sales }\end{array}$ & $\begin{array}{c}\text { Age-adjusted } \\
\text { repeat sales }\end{array}$ & Standard hedonic & Rolling hedonic \\
\hline Standard repeat sales & 0.6461 & 0.8740 & 0.0104 & 0.0001 \\
\hline Case-Shiller RS & 0.0369 & 0.0001 & 0.0001 & 0.0002 \\
\hline Age-adjusted RS & 0.7661 & 0.8889 & 0.0008 & 0.0070 \\
\hline Standard hedonic & 0.0001 & 0.0001 & 0.0001 & 0.2819 \\
\hline Rolling hedonic & & & & 0.0001 \\
\hline
\end{tabular}

Note: We regress the quarterly growth rate of index A, $y$, on the quarterly growth rate of index $\mathrm{B}, x$, to obtain the simple linear relationship $y=a+b x$. The number in each cell represents the $p$-value associated with the null hypothesis that $a=0$ and $b=1$ in the regression in which the index in the row is the dependent variable and the index in the column is the independent variable. 


\section{Table 7: Pairwise Granger-causality tests}

Condominiums

\begin{tabular}{|c|c|c|c|c|c|}
\hline & $\begin{array}{c}\text { Standard repeat } \\
\text { sales }\end{array}$ & $\begin{array}{c}\text { Case-Shiller repeat } \\
\text { sales }\end{array}$ & $\begin{array}{c}\text { Age-adjusted } \\
\text { repeat sales }\end{array}$ & Standard hedonic & Rolling hedonic \\
\hline Standard repeat sales & 0.2018 & 0.0120 & 0.0019 & 0.0039 & 0.0000 \\
\hline Case-Shiller RS & 0.0568 & n.a. & n.a. & 0.1258 & 0.0000 \\
\hline Age-adjusted RS & \multirow{2}{*}{0.0004} & 0.0001 & 0.0000 & 0.0000 \\
\hline Standard hedonic & 0.0053 & 0.0082 & 0.0022 & 0.1528 & 0.000 \\
\hline
\end{tabular}

Single family houses

\begin{tabular}{|c|c|c|c|c|c|}
\hline & $\begin{array}{c}\text { Standard repeat } \\
\text { sales }\end{array}$ & $\begin{array}{c}\text { Case-Shiller repeat } \\
\text { sales }\end{array}$ & $\begin{array}{c}\text { Age-adjusted } \\
\text { repeat sales }\end{array}$ & Standard hedonic & Rolling hedonic \\
\hline Standard repeat sales & 0.2397 & 0.2726 & 0.4345 & 0.1919 \\
\hline Case-Shiller RS & 0.3275 & n.a. & n.a. & 0.1810 & 0.0088 \\
\hline Age-adjusted RS & 0.0028 & 0.0028 & 0.0027 & 0.1962 \\
\hline Standard hedonic & 0.0812 & 0.0784 & 0.0781 & 0.0078 \\
\hline Rolling hedonic & & & & 0.1089 \\
\hline
\end{tabular}

Note: The number in each cell represents the p-value associated with the null hypothesis that the variable in the row does not Granger-cause the variable in the column. 
Figure 1: Estimated depreciation curves

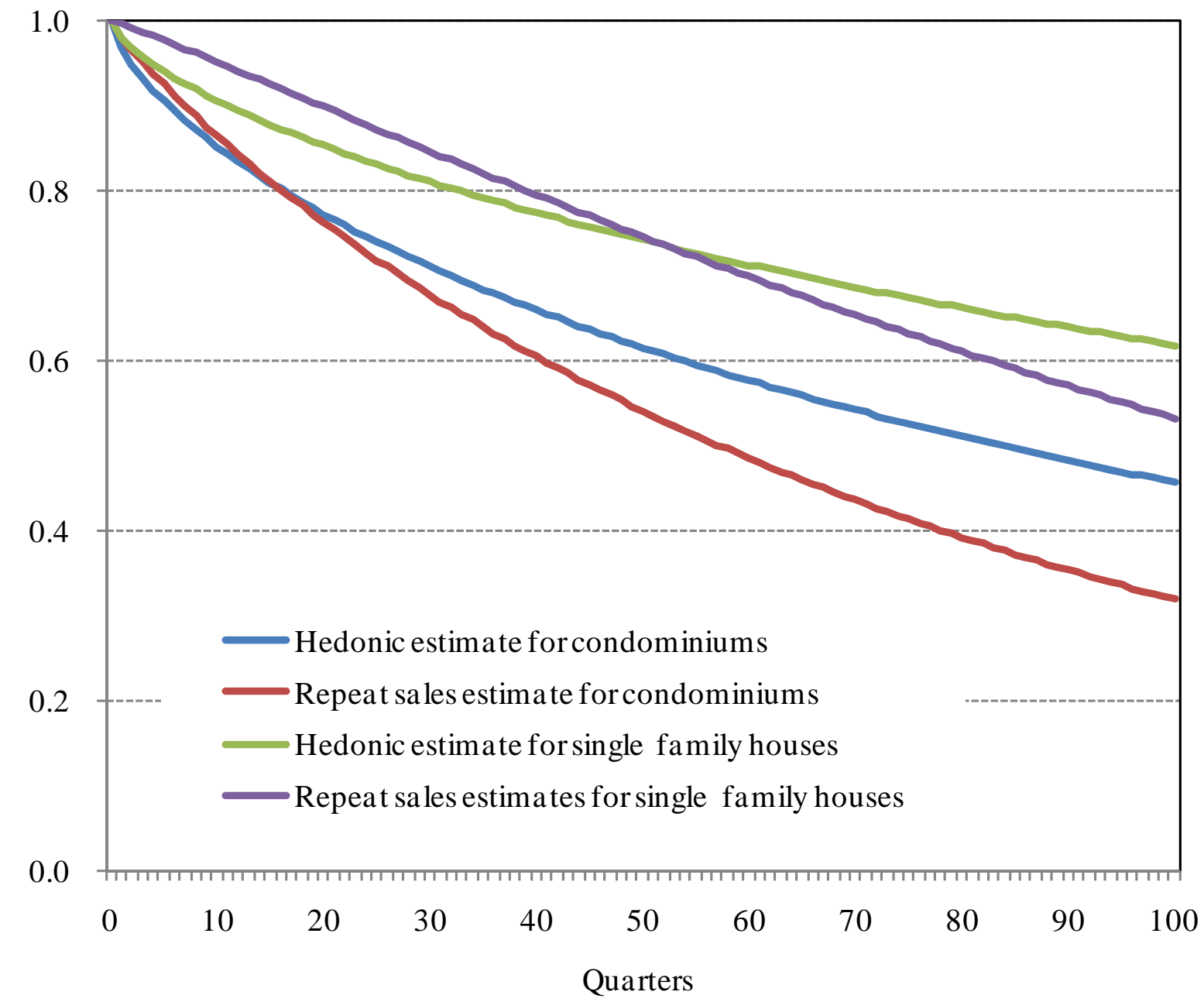


Figure 2a: Estimates of the five indexes for condominiums

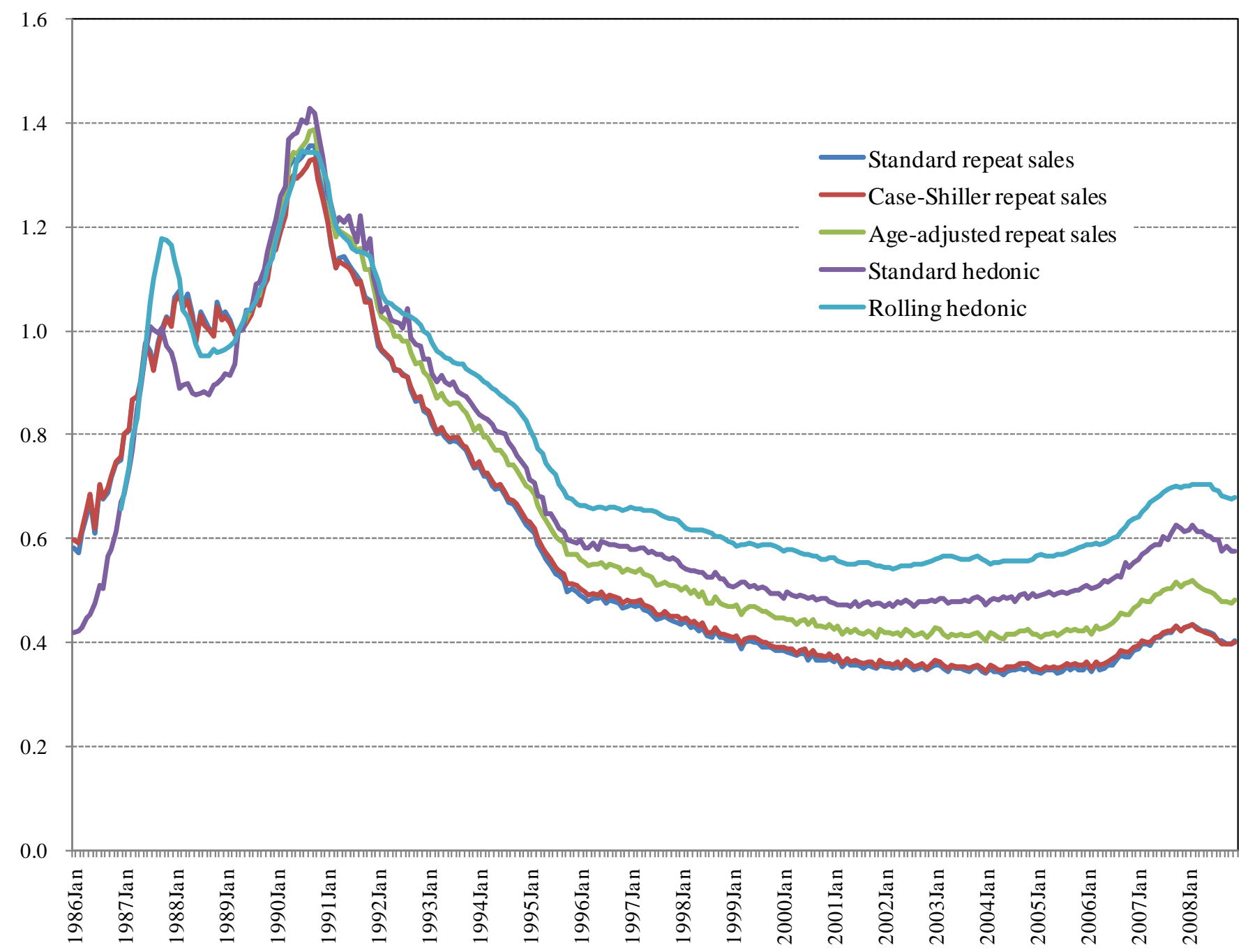


Figure 2b: Estimates of the five indexes for single family houses

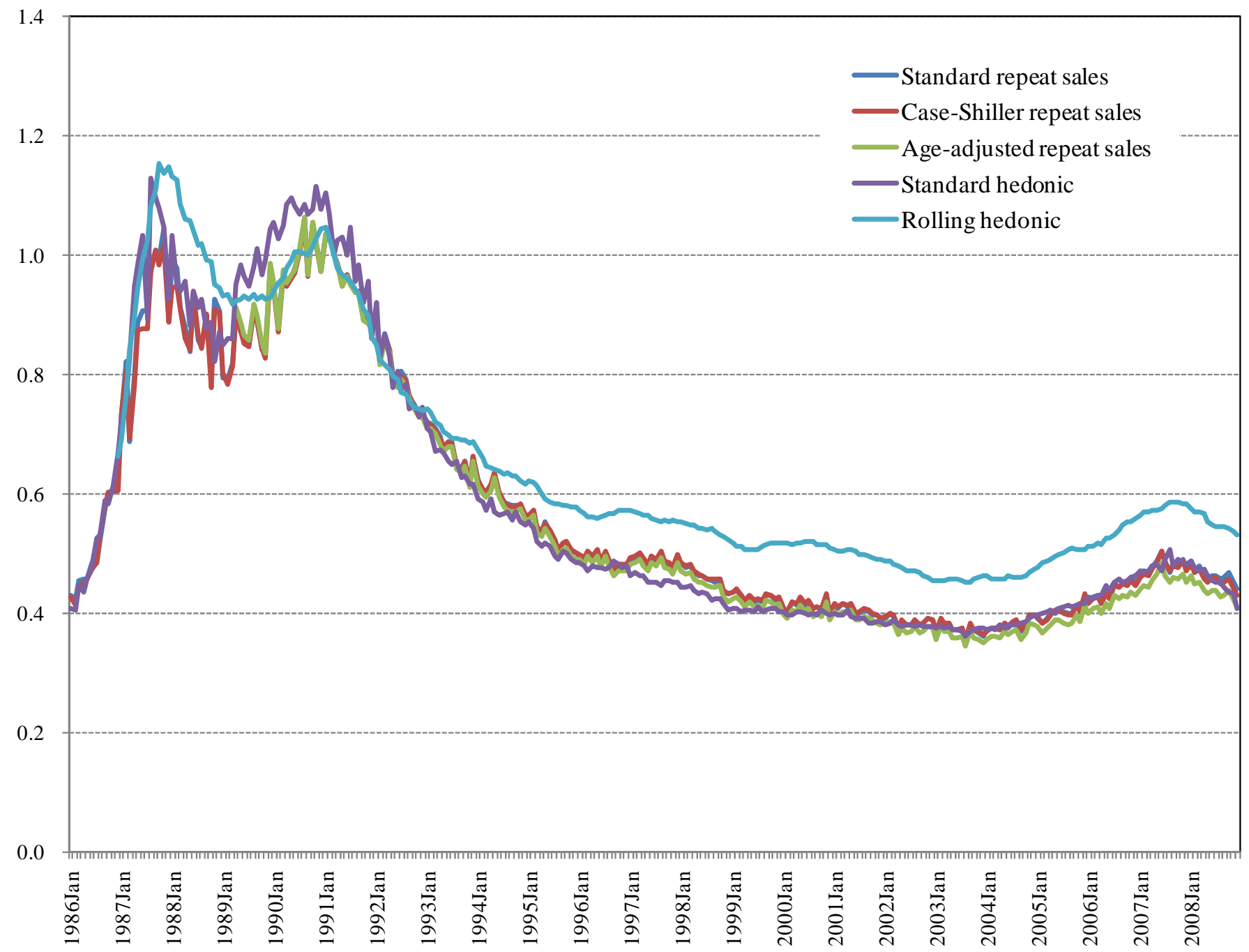


Figure 3: Comparison of the five indexes in terms of the quarterly growth rate

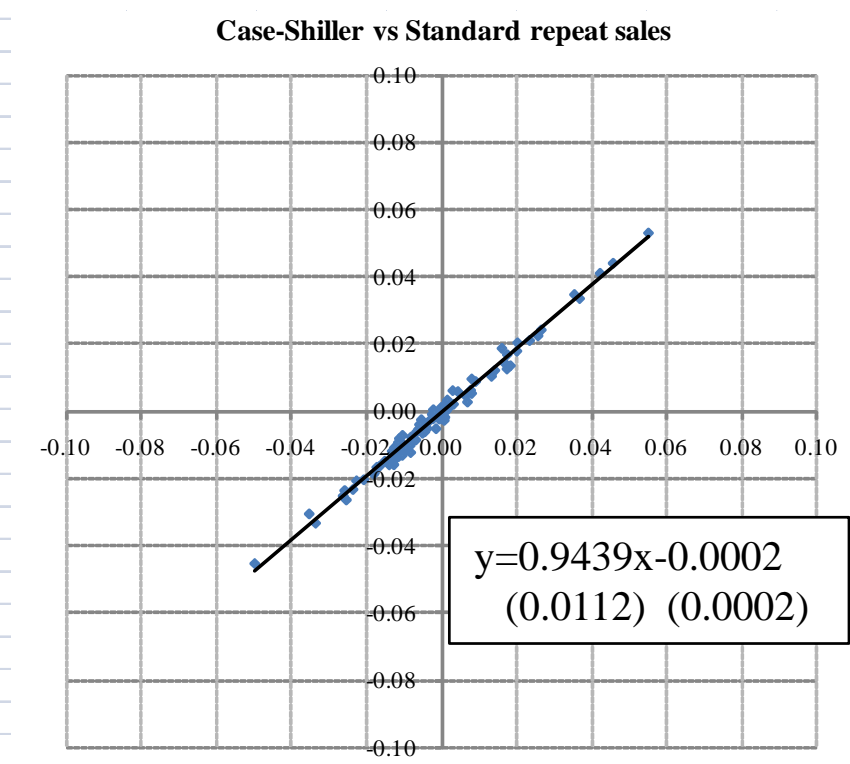

Age-adjusted repeat sales vs Standard repeat sales
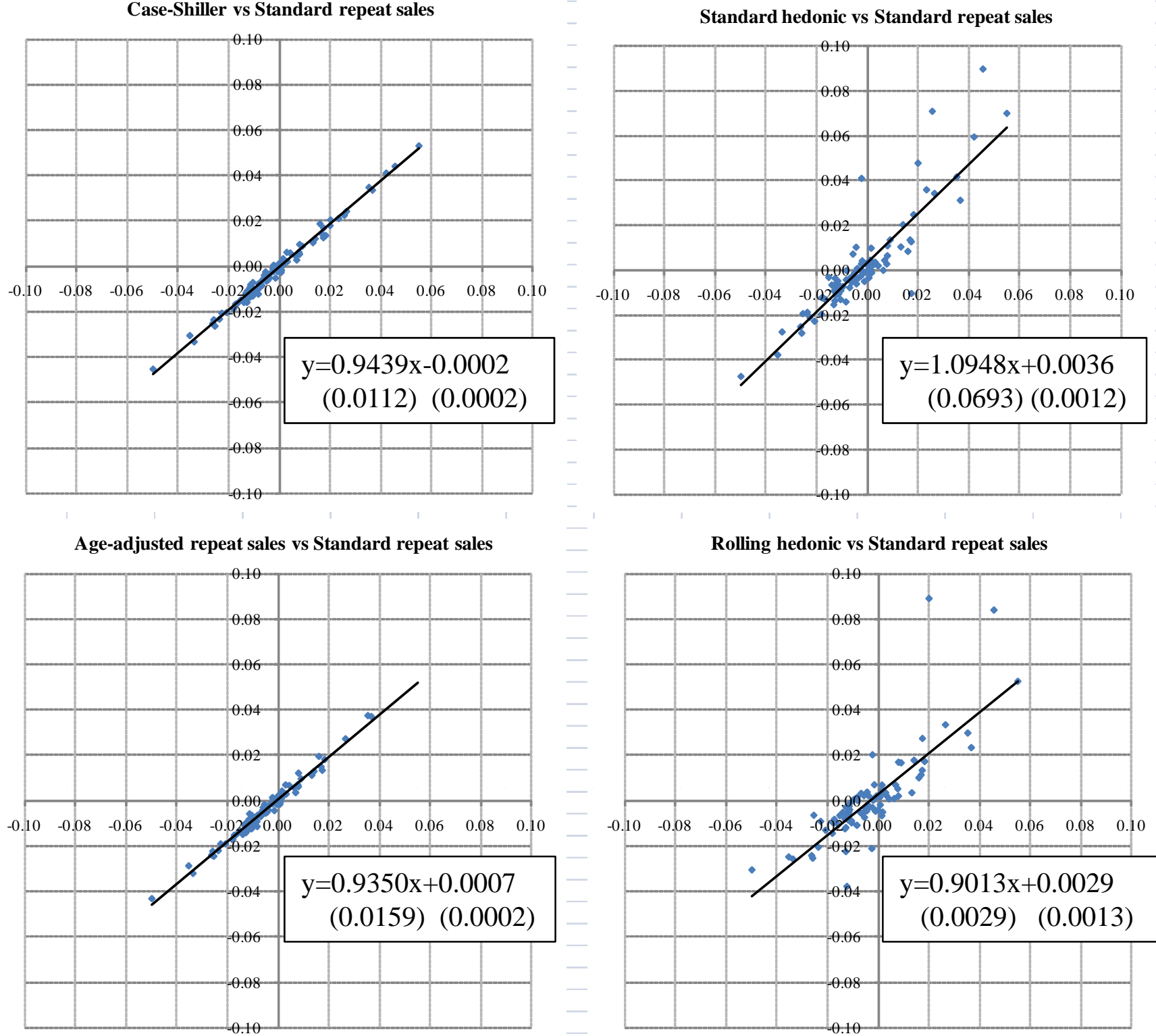

Rolling hedonic vs Standard repeat sales

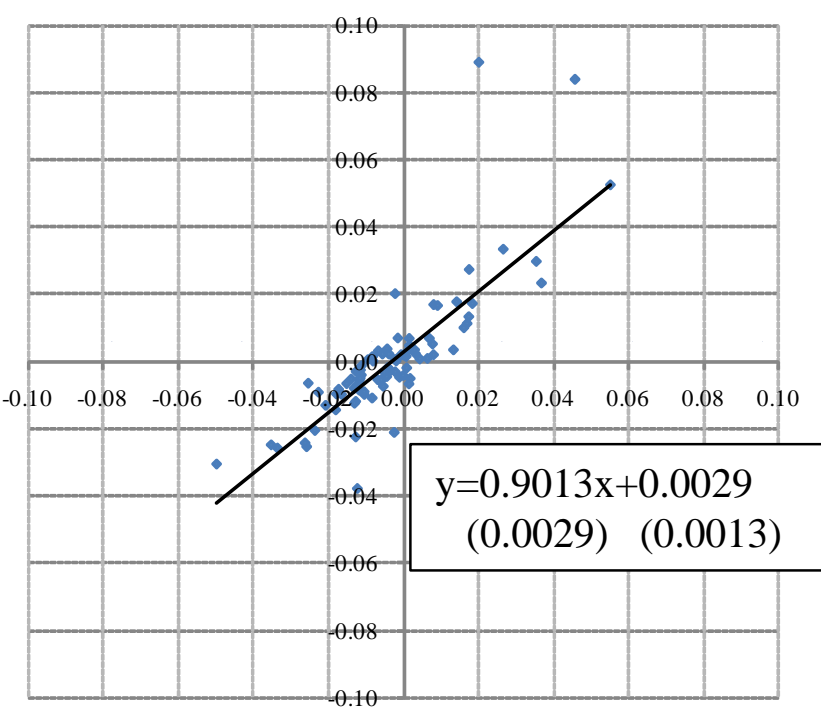


Figure 4: When did condominium prices bottom out?

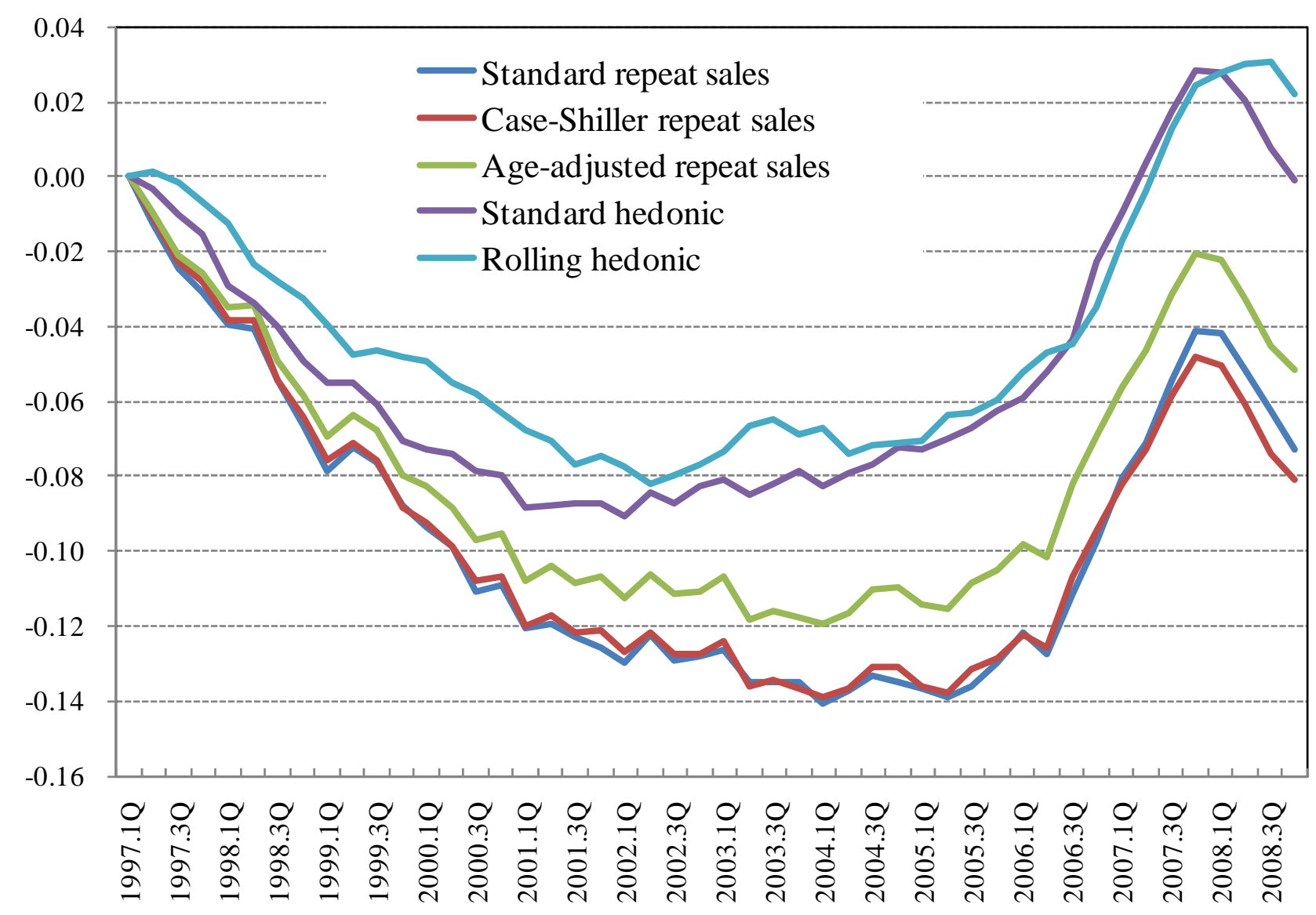


Figure 5: Hedonic indexes estimated using repeat sales samples

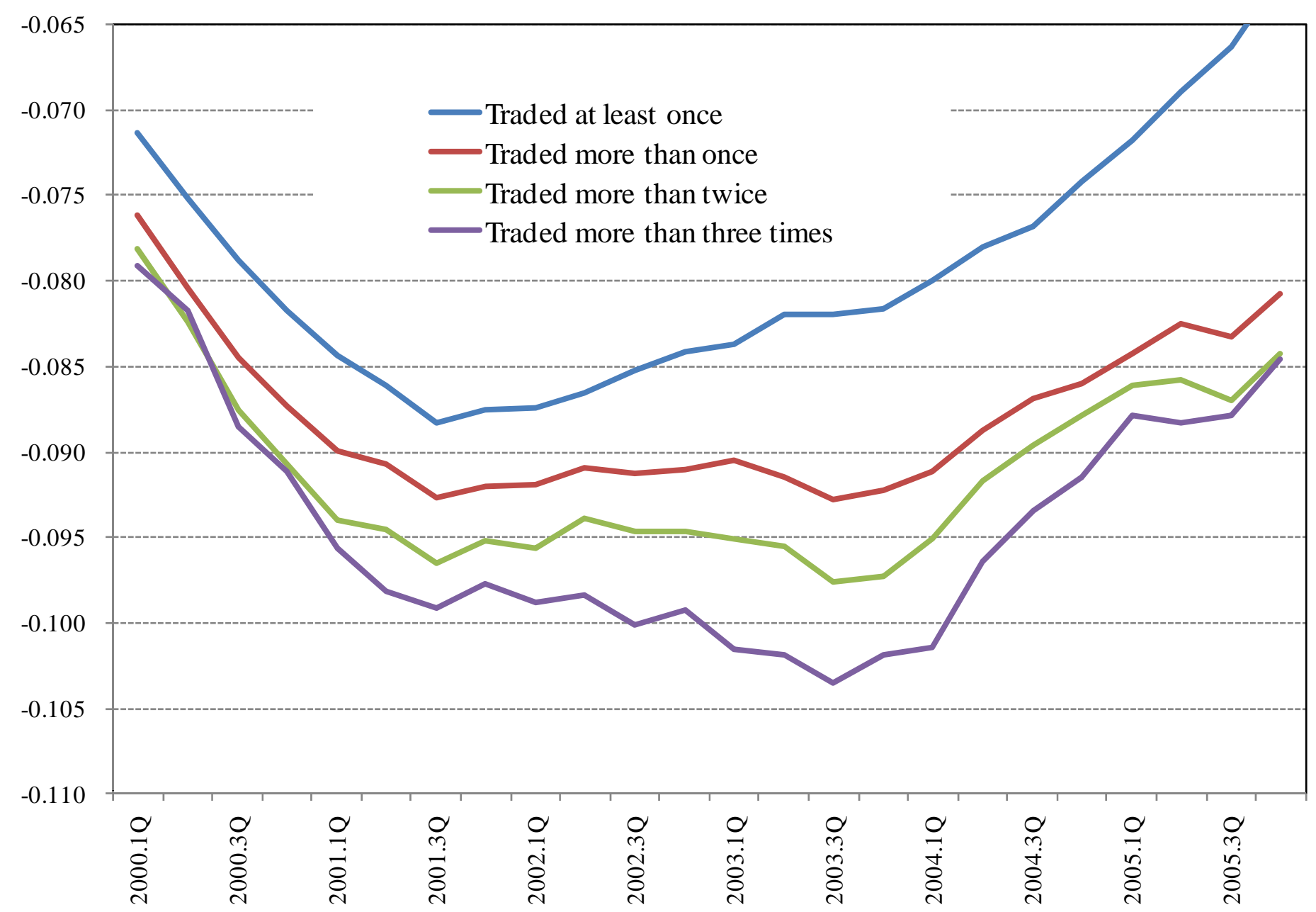

